\title{
The Efficacy of Energy Production and Economic Growth in Aggregate Energy Consumption: A Panel Data Evidence from Selected OIC Countries
}

\author{
Dr. Ahmed Saddam \\ Lecturer - Faculty of Administration and Economics, University of Basra - Iraq \\ Email: ahmed_saddam@live.com
}

\author{
Doi:10.5901/mjss.2015.v6n3p590
}

\begin{abstract}
This paper examines correlated variables of energy resources and growth, and their contribution in aggregate energy consumption. Its main objective is to identify the efficacy of energy, as well as to find out to which extent an economy is based on energy in order to extrapolate whether it is highly linked to energy-based industries or not. For this purpose, an empirical model is regressed for the logarithmic annual stationary data of selected OIC countries over the period 1991-2010. The results reveal that the GDP growth in Saudi Arabia has led to reduced levels of aggregate energy consumption, and does not for the UAE in the short-run. Moreover, the economies of Malaysia and Libya are highly linked to energy use especially natural gas in the long-run. And vice versa for Algeria and Indonesia in which the crude oil and natural gas production are not statistically significant.
\end{abstract}

Keywords: crude oil, natural gas, electricity, panel data, energy use efficiency.

\section{Introduction}

During the last two decades, the introduction of high levels of competition in the crude oil, electricity and natural gas sectors of several OIC member countries has raised the general question of the efficiency of these sectors (Konac 2004). Therefore, the increasing attention given to energy issues in OIC countries and their policies for achieving a better use is a major reason of this paper via examining the effect of energy production on the aggregate energy consumption over the period from 1991 to 2010.

A number of research papers related to energy sector have attracted many economists and policy makers in recent times due to its role in determining levels of economic growth particularly in producing oil countries. In this paper, we considered three components of energy supply; crude oil, electricity, and natural gas, and we added the per capita GDP variable. The main question is; what is the association between these variables and energy consumption? However, this study is an attempt to investigate how much the production of different energy sectors will affect aggregate energy consumption in oil countries like Saudi Arabia, Libya and the UAE, and other economies such as Malaysia, Indonesia and Algeria, which gas sector represents a main source of energy. Accordingly, our analysis is seeking to extrapolate the energy policy of these economies and its impact in this context. Analysing of diagnostic tests of data of this study combined into three samples, each one represents two countries due to their geographical location. Where, Saudi Arabia and the UAE as GCC, Libya and Algeria as NA, and Indonesia and Malaysia as EA. The main purpose for that is to analyse them as samples of various geographical areas of selected OIC member countries, while the econometric model will be estimated for each country by using a fixed panel data technique.

\section{Review of Literature}

Many studies which addressed the relationship between the energy and economic performance are varied notably due to the different economic structures of the countries studied. As well as, the period of these studies. It is also differentiated because of the differences of level of economic development. The majority of these studies have found a positive linkage running from different energy sectors to GDP. However, we will consider some literature which is commonly cited by many scholars in order to shed light on the mainstream of energy studies. (Costantini and Martini 2010) showed an empirical study for not stationary and co-integrated panel data with a large sample of developing and developed countries. (Kwakwa 2011) and (Siddiqui 2012) for the causal linkage between energy consumption and economic growth by using modern panel unit root technique. While the study of (Loganathan and Subramaniam 2010) represents that 
energy consumption in Malaysia is on sustainable limits, as well as it stated a bidirectional co-integration effect between total energy consumption and economic performance.

In addition, other studies are inferred a positive association between energy use and economic growth using different methods. For instance, (Gbadebo and Okonkwo 2009, Fatimah Kari and Ahmed 2014) found a positive linkage between economy and energy consumption in Nigeria and GCC countries. These evidences have also been found in other studies like (Sari, Ewing et al. 2008) and (Kaplan, Ozturk et al. 2011) which analyses the positive role of energy towards economies of many countries.

Although there are studies that pursued many methods, few studies have explicitly examined the association between energy consumption and its production using the disaggregate panel data approach for selected OIC countries. However, the disaggregate data allow for comparison of the relative strengths of the relationship with an energy source. Accordingly, our approach is on investigating the link between the aggregate energy consumption and the disaggregate energy productions in selected OIC countries. On the other hand, to pinpoint exactly the impact of the differences of energy sources on different economic structures. The conclusions would have particular relevance for assessment related energy policies in the OIC countries.

\section{Study Background}

In general, energy consumption is globally increased parallel to technological progress and population growth (Kaplan, Ozturk et al. 2011). Figure (1) below depicts trends of aggregate energy consumption for the period 1991 to 2010. It is obvious that Algeria, Libya, Malaysia and Indonesia have controlled a high level of energy consumption. It is a result of the urbanization process, economic growth, industrialization and population growth (Wee, Matsumoto et al. 2008). However, natural gas represented 63 percent of energy consumption in Algeria in 2002 and is the main source of Algeria's electricity generation (Grein, Nordell et al. 2007). In Indonesia, the industrial energy consumption has soared by 6 percent per year since 1990, faster than the economic growth rate of 4.5 percent a year (EER 2011).

Figure 1: Aggregate energy consumption in the countries of study, 1991-2010 (Thousand metric ton of oil equivalent)

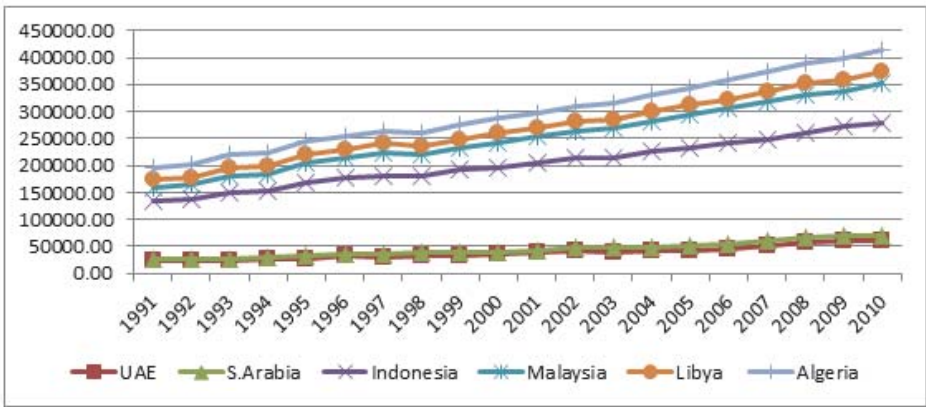

Source: By the author based on data of SESRIC- Statistical, Economic and social research and training centre for Islamic countries, Turkey (http://www.sesric.org/databases-index.php)

On the contrary, Saudi Arabia and the UAE represent a corresponding low level compared to the said countries at the mentioned period, but energy consumption of these economies has grown quickly and caused a shortage in the natural gas supply which is a major source for power generation (Marc Hormann and Joern Carlos Kuntze 2012). Moreover, the energy consumption trend is also hardly affected by the sharp increase of energy after the 1992-1994 period experienced by many countries caused by the inclusion of a specific energy source "combustible renewable and waste" which was highly consistent for Indonesia (Costantini and Martini 2010).

In Table (1) below, we note that the growth levels of energy consumption were positive -except that for crude oil production of Indonesia- over the period 1991 to 2010, on average. However, these levels have ranged from 0.02 to 0.05 for the production of natural gas and consumption of electricity. In contrast, the generation of electricity witnessed a high growth, particularly in the UAE, Malaysia and Indonesia by $0.08,0.07$ and 0.07 respectively. This fact could be explained by the positive growth levels of these economies, especially in Malaysia and Indonesia, where their GDP per capita growth rate rose by 0.06 and 0.07 respectively. Furthermore, we note that the growth levels of aggregate energy consumption are less than the growth of per capita GDP, and vice versa for the UAE and Saudi Arabia. 
Table 1: Growth of energy consumption and production, and GDP per capita, on average 1991-2010 (percentages)

\begin{tabular}{|c|c|c|c|c|c|}
\hline Country & Energy consumption & Crude oil production & Electricity production & Natural gas production & GDP per capita \\
\hline UAE & 0.05 & 0.00 & 0.08 & 0.03 & 0.02 \\
\hline S. Arabia & 0.04 & 0.00 & 0.05 & 0.04 & 0.03 \\
\hline Algeria & 0.02 & 0.02 & 0.05 & 0.02 & 0.04 \\
\hline Libya & 0.02 & 0.01 & 0.06 & 0.05 & 0.02 \\
\hline Malaysia & 0.05 & 0.00 & 0.07 & 0.05 & 0.06 \\
\hline Indonesia & 0.03 & -0.02 & 0.07 & 0.02 & 0.07 \\
\hline
\end{tabular}

Source: Calculated by the author based on data of SESRIC- Statistical, Economic and social research and training centre for Islamic countries, Turkey (http://www.sesric.org/databases-index.php).

This means, the achieved value added of non-oil countries is higher than that of oil countries, particularly the UAE and Saudi Arabia. Meaning that, Malaysia and Indonesia have reached economies of scale because of their growth levels are higher than the growth of energy consumption, where their growth is related to the growth of their manufactured industries (Yean 1997, Timmer and Szirmai 2000) . In Libya, the consumption growth was equal to its GDP per capita growth level, while is less in Algeria, as shown in Table above.

In respect of energy production, it is well known that Saudi Arabia and the UAE are major crude oil producers compared to other OIC member countries of the study. They are the dominant source of energy use. However, this feature could be considered a key factor for efficiency in terms of energy use for both two countries. Accordingly, the economic growth is still highly linked to oil sector and other industries that related to the energy sector despite of pursuing many economic policies to diversifying the non-oil industries (Fatimah Kari 2013). Furthermore, we noted that in Algeria and Malaysia, the natural gas and oil controlled at 36 percent and 20 percent of the GDP, respectively (Yean 1997, UEA 2012). While oil export revenues are extremely crucial to the growth of Libyan economy. It represents 90 percent of the total revenues (Mohamed Ekhlat 2007). Also, Algeria and Indonesia reached for the second rank in terms of natural gas production in comparison with other countries of this study (Timmer and Szirmai 2000). However, they produced 73385.80 and 67070.90 million standard cubic meters, as shown in the following figure:

Figure 2: Production of Natural Gas, on average, 1991-2010 (Million standard cubic meters)

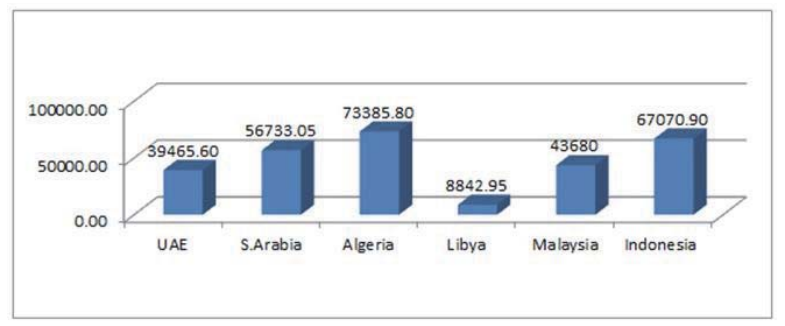

Source: By the author based on data of SESRIC- Statistical, Economic and social research and training centre for Islamic countries, Turkey (http://www.sesric.org/databases-index.php)

In respect of electricity generation, we see that Saudi Arabia and Indonesia have dominated on a higher level, which amounted by 139.21 and 97.20 billion kilowatt-hour on average for the period 1991-2010. However, through the previous presentation, we saw that the high positive growth of energy consumption and production is the mainstream for the countries of the study over the period 1991-2010. Therefore, our next analysis will be focusing on the impact of these main energy sources on the aggregate energy consumption, as well as the efficiency of energy use and the linkage between the economic growth and energy consumption for these economies.

\section{Data and Variables}

The study uses a panel data approach consists of six OIC countries which involves 120 balanced observations for the period 1991 to $2010(t=1 \ldots 20)$. For diagnostic tests, the data formed as samples, which are; GCC (Saudi Arabia and the UAE), EA (Malaysia and Indonesia), and NA (Libya and Algeria). In the panel data technique, the model is regressed for 
the full observations of each country selected for this study.

The variables used in the model are; aggregate energy consumption, crude oil production, electricity production, natural gas production, and GDP per capita. However, the major reason of this model is to empirically investigate the impact of crude oil, natural gas, and electricity on energy consumption in order to state which variable is leading for more efficiency over the period of the study.

\subsection{Model specification}

The model proposed is derived from the idea of Medlock and Soligo (Costantini and Martini 2010) which postulated that the energy consumption as a function of economic output. Accordingly, we selected three components of energy production as a main economic output and input of economic growth for the study variables; namely crude oil, electricity and natural gas, as follows:

\section{$E_{c t j}=f\left(P \mathrm{CO}_{t i}, \mathrm{PNG}_{t j,} \mathrm{Pe}_{t j}, \mathrm{Gdp}\right)$}

Where energy consumption $(E c)$ at time $t$ is a function of production of crude oil $(P c 0)$, Electricity $(P e)$ and natural gas (Png). However, in this specification, the economic growth is also expressed in terms of energy production variables, as well as GDP per capita. Therefore, a suitable representation of this relation could be represented by the following equation:

$\log _{10}(E c)=a+b 1 \log _{10}(P c 0)+b 2 \log _{10}(P e)+b 3 \log _{10}(P n g)+b 4 \log _{10}(G D P)+u i$

Where (a) intercept, $b 1, b 2, b 3$ and $b 4$ are the slope coefficients. (u) error term at time t. Furthermore, the variables of the model are measured as follows; $(E c)$ thousand metric ton of oil equivalent, $(P c 0)$ thousand barrels per day, $(P e)$ billion kilowatt-hours, (Png) million standard cubic meters, and (GDP) US dollar.

\subsection{Diagnostic tests and results}

In order to ensure the validity of the data of study, as well as the correlation between the variables used, we have conducted several diagnostic tests. These tests infer that the variables are statistically valid. Thus, it could be used for setting an economic analysis for the result of the estimators of this study. These tests are:

\subsubsection{Unit root test}

Prior to running the regression, the Augmented Dickey Fuller test (ADF) is essential for testing the stationary of panel data series (Lall 1998). However, the obtained values confirm that the regression result of this study is not spurious. However, we found that the variables in their levels were not stationary at both 1 percent and 5 percent significant levels. Table (2) illustrated that the data are stationary at the difference one, and statistically significant at their 1 percent and 5 percent levels. This implies that the variables of the study could be estimated by the model adopted.

Table 2: Unit root test of the variables of the study

\begin{tabular}{|c|c|c|c|c|}
\hline Variable & t-statistics & $\mathbf{1 \%}$ critical value & $\mathbf{5 \%}$ critical value & Prob(*) \\
\hline Log EC & -11.67185 & -2.584707 & -1.943563 & 0.0000 \\
\hline Log PCO_GCC & -10.81117 & -2.584707 & -1.943563 & 0.0000 \\
\hline Log PE_GCC & -13.10038 & -2.584707 & -1.943563 & 0.0000 \\
\hline Log PNG_GCC & -10.92187 & -2.584707 & -1.943563 & 0.0000 \\
\hline Log GDP_GCC & -10.96986 & -2.584707 & -1.943563 & 0.0000 \\
\hline Log PCO_EA & -10.81520 & -2.584707 & -1.943563 & 0.0000 \\
\hline Log PE_EA & -10.70325 & -2.584707 & -1.943563 & 0.0000 \\
\hline Log PNG_EA & -10.85689 & -2.584707 & -1.943563 & 0.0000 \\
\hline Log GDP_EA & -10.93444 & -2.584707 & -1.943563 & 0.0000 \\
\hline Log PCO_NA & -12.12554 & -2.584707 & -1.943563 & 0.0000 \\
\hline Log PE_NA & -11.68523 & -2.584877 & -1.943587 & 0.0000 \\
\hline Log PNG_NA & -11.04173 & -2.584707 & -1.943563 & 0.0000 \\
\hline Log GDP_NA & -11.21126 & -2.584707 & -1.943563 & 0.0000 \\
\hline
\end{tabular}

*MacKinnon (1996) one-sided p-values.

Source: By the author based on Eviews software. 


\subsubsection{Correlation test}

For measuring the strength and direction of the linear association between the variables of study, we have conducted the Pearson correlation test. As well known, the degree of correlation of coefficients will vary from -1 to +1 . A negative sign indicates a presence of perfect negative linkage between the variables. And vice versa in terms of obtaining a positive sign (Olayiwola and Okodua 2009). Table (3) illustrates the strength of a linear association between the variables of the GCC sample - Saudi Arabia and the UAE. However, the pearson correlation test shows that there is a large positive strength ${ }^{(*)}$ between the aggregate energy consumption and the production of crude oil, electricity generation, and natural gas production, which amounted to be $0.91,0.79$ and 0.85 respectively. Whereas the linkage between EC and per capita GDP was a medium negative, $(-0.412)$. Accordingly, we can say that a positive relationship implies as a value of one variable increases so does the value of another variable, and vice versa in terms of a negative correlation.

Table 3: Pearson correlation test for the GCC sample

\begin{tabular}{ll|c|c|c|c|c|}
\hline & & EC_GCC & PCO_GCC & PE_GCC & PNG_GCC & GDP_GCC \\
\hline EC_GCC & Pearson Correlation & 1 & $.912^{* *}$ & $.798^{* *}$ & $.857^{* *}$ & $-.412^{* *}$ \\
& Sig. (2-tailed) & & .000 & .000 & .000 & .008 \\
& N & 40 & 40 & 40 & 40 & 40 \\
PCO_GCC & Pearson Correlation & $.912^{* *}$ & 1 & $.634^{* *}$ & $.595^{* *}$ & $-.707^{* *}$ \\
& Sig. (2-tailed) & .000 & & .000 & .000 & .000 \\
& N & 40 & 40 & 40 & 40 & 40 \\
PE_GCC & Pearson Correlation & $.798^{* *}$ & $.634^{* *}$ & 1 & $.798^{* *}$ & -.119 \\
& Sig. (2-tailed) & .000 & .000 & & .000 & .463 \\
& N & 40 & 40 & 40 & 40 & 40 \\
PNG_GCC & Pearson Correlation & $.857^{* *}$ & $.595^{* *}$ & $.798^{* *}$ & 1 & .066 \\
& Sig. (2-tailed) & .000 & .000 & .000 & & .686 \\
& $N$ & 40 & 40 & 40 & 40 & 40 \\
GDP_GCC & Pearson Correlation & $-.412^{* *}$ & $-.707^{* *}$ & -.119 & .066 & 1 \\
& Sig. (2-tailed) & .008 & .000 & .463 & .686 & \\
& $\mathrm{~N}$ & 40 & 40 & 40 & 40 & 40 \\
\hline
\end{tabular}

Therefore, it is clear that the correlation result is fit for these variables to be estimated in order to test how much the energy produced components affect the level of aggregate energy consumption over the period of the study, 1991-2010.

Table 4: Pearson correlation test for the EA region (Malaysia and Indonesia)

\begin{tabular}{|c|c|c|c|c|c|c|}
\hline & & EC_EA & PCO_EA & PE_EA & PNG_EA & GDP_EA \\
\hline \multirow[t]{3}{*}{ EC_EA } & Pearson Correlation & 1 & $.739^{*+}$ & $.690^{* *}$ & $.899^{\text {t* }}$ & $-.672^{*+}$ \\
\hline & Sig. (2-tailed) & & .000 & .000 & .000 & .000 \\
\hline & $\mathrm{N}$ & 40 & 40 & 40 & 40 & 40 \\
\hline \multirow{3}{*}{ PCO_EA } & Pearson Correlation & $.739^{*+2}$ & 1 & 101 & $.589^{*+*}$ & $-.917^{* *}$ \\
\hline & Sig. (2-tailed) & .000 & & .534 & .000 & .000 \\
\hline & $\mathrm{N}$ & 40 & 40 & 40 & 40 & 40 \\
\hline \multirow[t]{3}{*}{ PE_EA } & Pearson Correlation & $.690^{* *}$ & .101 & 1 & $.817^{7 *}$ & -.022 \\
\hline & Sig. (2-tailed) & .000 & .534 & & .000 & .891 \\
\hline & $\mathrm{N}$ & 40 & 40 & 40 & 40 & 40 \\
\hline
\end{tabular}

\begin{tabular}{lrc}
\hline${ }^{*}$ Strength of association & positive & negative \\
Small & 0.1 to 0.3 & -0.1 to -0.3 \\
Medium & 0.3 to 0.5 & -0.3 to 0.5 \\
Large & 0.5 to 1.0 & -0.5 to 1.0
\end{tabular}

Source: Deliitte (2011). "Energy on demand: the future of GCC energy efficiency " Deloitte. from http://www.deloitte.com/assets/DcomMiddleEast/Local\%20Assets/Documents/Industries/Energy\%20\&\%20resources/E\&R\%20whitepapers/me_er_whitepaper4_energy_effici ency.pdf. 


\begin{tabular}{|ll|c|c|c|c|c|} 
IPNG_EA & Pearson Correlation & $.899^{* *}$ & $.589^{* *}$ & $.817^{* *}$ & 1 & $-.414^{* *}$ \\
& Sig. (2-tailed) & .000 & .000 & .000 & & .008 \\
& $\mathrm{~N}$ & 40 & 40 & 40 & 40 & 40 \\
GDP_EA & Pearson Correlation & $-.672^{* *}$ & $-.917^{* *}$ & -.022 & $-.414^{* *}$ & 1 \\
& Sig. (2-tailed) & .000 & .000 & .891 & .008 & \\
& $\mathrm{~N}$ & 40 & 40 & 40 & 40 & 40 \\
\hline
\end{tabular}

**. Correlation is significant at the 0.01 level (2-tailed).

Source: By the author based on SPSS software.

Furthermore, Table (4) shows the association between the variables of EA sample- Malaysia and Indonesia. However, we have found that all variables are correlated, and the production of natural gas (PNG) dominated on a significant level of correlation with energy consumption. This means the important role of natural gas of these countries as a main source of energy, where the positive relationship is amounted to be a 0.899 . Moreover, PCO and PE are situated at the second and third rank, 0.73 and 0.69 respectively. While the per capita GDP has a large negative correlation. This implies the increase of economic growth and per capita by one time have led to reduce the level of energy consumption by 0.67 times over the period 1991-2010. Meaning that, the economic growth of EA sample has led to achieving an efficiency in term of using energy sources. However, this result could be attributed to the role of advanced technologies used in the manufacturing sectors of these economies (Lall 1998). Furthermore, it is worth noting that the growth levels of natural gas production in Malaysia and Indonesia were less than that of per capita GDP. However, the PNG have grown by 0.05 percent and 0.02 percent while the per capita GDP by 0.06 percent and 0.07 percent in both two countries, respectively as shown in Table 1. Again these percentages confirm that the economic growth in Malaysia and Indonesia was not leading to increasing levels of PNG consumption.

Table 5: Pearson correlation test for the sample of NA ( Algeria and Libya)

\begin{tabular}{|ll|c|c|c|c|c|}
\hline & & EC_NA & PCO_NA & PE_NA & PNG_NA & GDP_NA \\
\hline EC_NA & Pearson Correlation & 1 & -.075 & -.274 & $.831^{* *}$ & .306 \\
& Sig. (2-tailed) & & .642 & .083 & .000 & .052 \\
& $\mathrm{~N}$ & 41 & 41 & 41 & 41 & 41 \\
PCO_NA & Pearson Correlation & -.075 & 1 & $.943^{* *}$ & $-.446^{* *}$ & $.899^{* *}$ \\
& Sig. (2-tailed) & .642 & & .000 & .003 & .000 \\
& $\mathrm{~N}$ & 41 & 41 & 41 & 41 & 41 \\
PE_NA & Pearson Correlation & -.274 & $.943^{* *}$ & 1 & $-.593^{* *}$ & $.788^{* *}$ \\
& Sig. (2-tailed) & .083 & .000 & & .000 & .000 \\
& N & 41 & 41 & 41 & 41 & 41 \\
PNG_NA & Pearson Correlation & $.831^{* *}$ & $-.446^{* *}$ & $-.593^{* *}$ & 1 & -.165 \\
& Sig. (2-tailed) & .000 & .003 & .000 & & .303 \\
& N & 41 & 41 & 41 & 41 & 41 \\
GDP_NA & Pearson Correlation & .306 & $.899^{*+*}$ & $.788^{* *}$ & -.165 & 1 \\
& Sig. (2-tailed) & .052 & .000 & .000 & .303 & \\
& N & 41 & 41 & 41 & 41 & 41 \\
\hline
\end{tabular}

Source: By the author based on SPSS software.

${ }^{*}$. Correlation is significant at the 0.01 level (2-tailed).

Table (5) illustrates that the PNG variables of Algeria and Libya have a large association with the energy consumption, while other variables were not statistically significant. This confirms the significance of the PNG as a major energy source, which positively influenced the level of aggregate energy consumption over the period of the study. It is a crucial determinant of economic growth of NA sample.

\subsubsection{Cointegration test}

The Johansen trace test for cointegration is regressed to find out whether there is a long-run association between the variables of each sample in the study. Table (6) shows the presence of cointegration in the EA and NA samples, while in the GCC sample did not exist. Table 6 below states that there is no cointegration between aggregate energy consumption (EC) of GCC sample and the energy producing components, PCO, PE, PNG and per capita GDP. However, there is no 
significance at 0.01 level, and this means the long -run relationship does not exist in the case of GCC sample. Whereas, the above table illustrated a log-run relationship for the variables of the samples EA and NA. This means, the variables involved in the regression equation will move together (Engle and Granger 1987). However, the regression result will be analysed as a short-run relationship for the variables of GCC sample, and as a long-run relationship for EA and NA samples.

Table 6: Johansen trace test result for cointegration

\begin{tabular}{|c|c|c|c|c|c|}
\hline Variable & Hypothesized No. of CE(s) & Eigenvalue & Trace statistics & 0.5 Critical value & Prob.** \\
\hline \multirow{5}{*}{$\begin{array}{c}\text { Log EC_GCC, Log } \\
\text { PCO_GCC, } \\
\text { Log PE_GCC, Log } \\
\text { PNG_GCC, Log DP_GCC }\end{array}$} & None & 0.519775 & 55.15858 & 69.81889 & 0.4124 \\
\hline & At most 1 & 0.426834 & 28.75257 & 47.85613 & 0.7800 \\
\hline & At most 2 & 0.132748 & 8.715690 & 29.79707 & 0.9934 \\
\hline & At most 3 & 0.084254 & 3.588368 & 15.49471 & 0.9339 \\
\hline & At most 4 & 0.011592 & 0.419763 & 3.841466 & 0.5171 \\
\hline \multirow{5}{*}{$\begin{array}{c}\text { Log EC_EA, Log } \\
\text { PCO_EA, Log PE_EA, } \\
\text { Log PNG_EA, Log } \\
\text { GDP_EA }\end{array}$} & None * & 0.735467 & 83.49730 & 69.81889 & 0.0028 \\
\hline & At most 1 & 0.423102 & 35.62492 & 47.85613 & 0.4155 \\
\hline & At most 2 & 0.201711 & 15.82166 & 29.79707 & 0.7248 \\
\hline & At most 3 & 0.147485 & 7.711431 & 15.49471 & 0.4968 \\
\hline & At most 4 & 0.053176 & 1.967126 & 3.841466 & 0.1608 \\
\hline \multirow{5}{*}{$\begin{array}{c}\text { Log EC_NA, Log } \\
\text { PCO_NA, Log } \\
\text { PE_NA, Log PNG_NA, } \\
\text { Log GDP_NA }\end{array}$} & None * & 0.964129 & 243.1253 & 69.81889 & 0.0000 \\
\hline & At most 1 * & 0.851687 & 123.3236 & 47.85613 & 0.0000 \\
\hline & At most 2* & 0.690817 & 54.62018 & 29.79707 & 0.0000 \\
\hline & At most 3 & 0.274318 & 12.36258 & 15.49471 & 0.1404 \\
\hline & At most 4 & 0.022505 & 0.819444 & 3.841466 & 0.3653 \\
\hline
\end{tabular}

Source: By the author based on Eviews oftware.

${ }^{*}$ ) denotes rejection of the hypothesis at the 0.05 level.

$\left.{ }^{* *}\right)$ MacKinnon-Haug-Michelis (1999) p-values.

\section{Model Estimation}

To indicate an ideal choice between fixed effect and random effect estimators in panel data context (Skrabic and TomicPlazibat 2009), the Hausman test is used. However, we have found that the probability is less than 0.05 (Prob.< 0.05 ) and statistically significant at 0.01 level, as shown in Table 7. Therefore, fixed effect regression is preferred. As well as, Durban-Watson value is amounted by 2.01 and this means that the model adopted is apart from auto-correlation statistic problem. However, this model is reliable and it could be used for analysing the result presented in Table 8.

Table 7: Hausman test result for the model of study

\begin{tabular}{|c|c|c|c|}
\hline \multicolumn{5}{|c|}{ Test Period Random effecs } \\
\hline Test Summary & Chi-Sq. Statistic & Chi-Sq. d.f. & Prob. \\
\hline Period random & 175.676308 & 12 & 0.0000 \\
\hline
\end{tabular}

Source: By the author based on Eviews software.

\subsection{The model result}

All GDP per capita variables -except for Indonesia- are statistically significant at 1 percent and 5 percent levels, therefore we can say that a one time increase of this variable is leading to rising level of aggregate energy consumption by 0.18 , $0.28,0.46$ and 0.51 times in Algeria, Malaysia, Libya, and the UAE respectively. Accordingly, it can seen that Algeria and Malaysia have achieved an efficiency for the total GDP, where a one unit of GDP has produced with a relatively low level of energy. In Saudi Arabia, the increase of level of GDP per capita by one time has effected in dropping level of aggregate energy consumption by 0.21 times. This result could be explained by the growing of non-oil industries in this country, in which the value added achieved does not cause in consuming a high level of energy as other energy-based industries. 
Table 8: Regression result of the model, fixed effects

Dependent Variable: EC

Method: Panel Generalized Method of Moments

Sample: 19912010

Cross-sections included: 6

Total panel (balanced) observations: 120

\begin{tabular}{|c|c|c|c|c|}
\hline Variable & Coefficient & Std. Error & t-Statistic & Prob. \\
\hline GDP_ALG & 0.188631 & 0.086564 & 2.179079 & $\left.0.0319{ }^{(* *}\right)$ \\
\hline GDP_IN & 0.044983 & 0.051950 & 0.865900 & 0.3888 \\
\hline GDP_KSA & -0.216433 & 0.098095 & -2.206357 & $\left.0.0299{ }^{(* *}\right)$ \\
\hline GDP_LY & 0.467797 & 0.057044 & 8.200694 & $0.0000\left(^{*}\right)$ \\
\hline GDP_MY & 0.289433 & 0.052548 & 5.508022 & $0.0000\left(^{*}\right)$ \\
\hline GDP_UAE & 0.515065 & 0.216886 & 2.374823 & $0.0197\left(^{(* *}\right)$ \\
\hline PCO_ALG & -0.079843 & 0.090675 & -0.880536 & 0.3809 \\
\hline PCŌ_IN & -0.022307 & 0.196530 & -0.113504 & 0.9099 \\
\hline PCO_K KSA & 0.367640 & 0.176956 & 2.077577 & $\left.0.0406{ }^{(* *}\right)$ \\
\hline PCO_LY LY & -0.208123 & 0.091883 & -2.265092 & $0.0259{ }^{(* *)}$ \\
\hline PCO_MY & -0.313152 & 0.181500 & -1.725357 & 0.0879 \\
\hline PCO_UAE & -0.042509 & 0.152740 & -0.278310 & 0.7814 \\
\hline PE_ALG & 0.464068 & 0.129373 & 3.587046 & $0.0005\left(^{*}\right)$ \\
\hline PE_IN & 0.368870 & 0.090338 & 4.083224 & $0.0001\left(^{\star}\right)$ \\
\hline PE_E KSA & 0.002408 & 0.012980 & 0.185508 & 0.8532 \\
\hline PE_LY & -0.071694 & 0.031288 & -2.291398 & $\left.0.0243^{(* *}\right)$ \\
\hline PE_MY & 0.066164 & 0.167924 & 0.394013 & 0.6945 \\
\hline PE_UAE & 0.449979 & 0.068523 & 6.566816 & $0.0000\left(^{*}\right)$ \\
\hline PNG_ALG & -0.016580 & 0.111748 & -0.148373 & 0.8824 \\
\hline PNG_IN & 0.124094 & 0.238066 & 0.521259 & 0.6035 \\
\hline PNG_KESA & 1.126528 & 0.093495 & 12.04906 & $0.0000\left(^{*}\right)$ \\
\hline PNG_LY & 0.420888 & 0.042286 & 9.953361 & $0.0000\left(^{*}\right)$ \\
\hline PNG_MY & 0.646959 & 0.188679 & 3.428886 & $0.0009\left(^{*}\right)$ \\
\hline PNG_UAE & 0.031726 & 0.095707 & 0.331487 & 0.7410 \\
\hline $\bar{C}$ & 1.838164 & 0.295218 & 6.226458 & 0.0000 \\
\hline
\end{tabular}

Effects Specification

\begin{tabular}{lccc}
\hline \hline \multicolumn{4}{c}{ Cross-section fixed (dummy variables) } \\
\hline \hline R-squared & 0.997876 & Mean dependent var & 4.726579 \\
Adjusted R-squared & 0.997192 & S.D. dependent var & 0.311565 \\
S.E. of regression & 0.016511 & Sum squared resid & 0.024534 \\
Durbin-Watson stat & 2.076402 & J-statistic & 90.00000 \\
Instrument rank & 31.00000 & & \\
$(*)$ Statistically significant at the (1\%) level. & & \\
\end{tabular}

Source: By the author based on Eviews software and fixed effect panel data technique.

On the other words, we can say that Saudi Arabia has a sound economic policy for reducing level of energy consumed aside to accomplish a high level of value added.

Besides, the model reveals that only crude oil production variable of Libya and and Saudi Arabia are statistically significant at 0.01 and 0.05 levels. However, rising of oil production level by one time has led to increasing levels of aggregate energy consumption by 0.20 and 0.36 times in both both countries respectively. In this context, Libya's oil sector has a high efficiency in terms of energy used in the oil producing process. However, this analysis is consistent with the level of growth of crude oil production, and if we revert to Table 1 we will clearly see that the growth level of this sector in Libya is amounted by 1 percent on average for the period of the study. While in Saudi Arabia is about 0 percent for the same duration. This fact infers the necessity of accomplishing a positive growth level which enhances level of 
efficiency of energy use. On the contrary, the model depicts that the crude oil production variables of the rest countries of study are not statistically significant. This implies that the crude oil sector does not affect substantially as other energy resources.

In respect of electricity generation, the result illustrates that its increase by one time will cause in rising of level of aggregate energy consumption by $0.36,0.44$ and 0.46 times in Indonesia, the UAE, and Algeria respectively. Hence, we can say that the electricity generation of Algeria and the UAE is costly in comparison to Indonesia. However, this result could be attributed to the demand- supply gas imbalance as an input for power generation, due this factor, the UAE started since 2009 to import natural gas from other countries (Kombargi, Waterlander et al. 2010). Furthermore, we noted that the increase of level of electricity generation by one time in Libya has led to bridge level of energy consumption by 0.07 times. The main reason pertains to this result is that using of electricity power as a good substitution for other energy sources, notably, Libya consume a lower level compared to other countries of this study. It generates only 17.95 billion kilowatt - hour, while in the UAE, Indonesia and Algeria are about 46.58, 97.20 and 27.96 billion kilowatt-hour. However, we can say also that Libya has an active policy which affected gradually in reducing level of energy consumption of electricity sector over the period of study. In contrast, we see that the electricity variable of Saudi Arabia and Malaysia is not statistically significant. Meaning that, the electricity generation is not an important element in its impact on the aggregate energy consumption.

Finally, the result pertaining to natural gas production illustrated that its rising by one time will affect positively in increasing level of aggregate energy consumed by 1.12, 0.42, and 0.64 for Saudi Arabia, Libya, and Malaysia. However, this result reveals that Saudi Arabia has not achieved an efficiency, where producing natural gas is costly compared other countries such as Libya and Malaysia.

\section{Concluding Remarks}

The empirical analysis is carried out on the full observations of a fixed model regressed, and on separate sub-samples, correlation test and cointegration test. However, the study found a large positive association between the variables used for the GCC and the EA samples, except for GDP per capita. It was a large negative, where the pearson correlation test showed this fact. According to the empirical results of the model adopted, we can conclude that the growth level in the UAE is accompanied with high level of energy consumption, particularly for electricity sector as a main factor of consuming natural gas. However, this finding could be linked to growing of urbanization, as well as, energy-based industries. While in Saudi Arabia the growth level has led to bridge level of energy use despite of oil sector And natural gas production have not accomplished an efficiency. This case, however, could be explained by the role of other non-oil industries which is not based on a high level of energy use. Hence, these industries influenced positively more than that of energy sectors. In Malaysia, the growth level coupled with high level of energy use in comparison to other countries of study. This finding is a reflection of growing of the industry sector in this country. Furthermore, natural gas production does not achieve efficiency. Therefore, we can say that the Malaysian economy is highly linked to energy use especially natural gas as a major source of energy. In addition, the electricity sector in Indonesia is efficient compared to the rest countries of study. And vice versa for Algeria, the electricity generation sector has led for consuming a high level of energy. While its GDP per capita growth level has an efficiency, hence, this means that the economic growth in Algeria is based on sectors in which does not rely on a high level of energy use. Whereas the Libyan economy is highly linked to natural gas production, which ensure that the growth level achieved is related to energy sector more than other components of the economy.

\section{References}

Costantini, V. and C. Martini (2010). "The causality between energy consumption and economic growth: A multi-sectoral analysis using non-stationary cointegrated panel data." Energy Economics 32(3): 591-603.

Deliitte (2011). "Energy on demand: the future of GCC energy efficiency " Deloitte. from http://www.deloitte.com/assets/DcomMiddleEast/Local\%20Assets/Documents/Industries/Energy\%20\&\%20resources/E\&R\%20whitepapers/me_er_whitepaper4_energ y_efficiency.pdf.

EER (2011). "Energy efficiency report-Indonesia ". from http://www05.abb.com/global/scot/scot316.nsf/veritydisplay/1a65dd16a 3c538 acc125786400514251/\$file/Indonesia.pdf.

Engle, R. F. and C. W. J. Granger (1987). "Co-integration and error correction: representation, estimation, and testing." Econometrica: journal of the Econometric Society: 251-276.

Fatimah Kari, A. S. (2013). "An empirical analysis to the role of FDI and foreign trade in GCC countries." International Journal of Economic research 10(1). 
Fatimah Kari, S. and Ahmed (2014). "A Long-Run Dynamic Analysis of FDI, Growth and Oil Export in GCC Countries: An Evidence from VECM Model." Canadian Social Science 10(1).

Gbadebo, O. O. and C. Okonkwo (2009). "Does energy consumption contribute to economic performance? Empirical evidence from Nigeria." Journal of Economics and International Finance 1(2): 044-058.

Grein, M., et al. (2007). "Energy consumption and future potential of renewable energy in North Africa." Gas 64(26.5): 0.4.

Kaplan, M., et al. (2011). "Energy Consumption and Economic Growth in Turkey: Cointegration and Causality Analysis." Romanian Journal of Economic Forecasting 14(2): 31-41.

Kombargi, R., et al. (2010). "Gas Shortage in the GCC: How to Bridge the Gap." Abu Dhabi: Booz \& Company.

Konac, H. (2004). "ENVIRONMENTAL ISSUES AND SUSTAINABLE DEVELOPMENT IN OIC COUNTRIES." Journal of Economic Cooperation 25.(4): 1-60.

Kwakwa, P. A. (2011). "Disaggregated energy consumption and economic growth in Ghana." International Journal of Energy Economics and Policy 2(1): 34-40.

Lall, S. (1998). "Technological capabilities in emerging Asia." Oxford Development Studies 26(2): 213-243.

Loganathan, N. and T. Subramaniam (2010). "Dynamic cointegration link between energy consumption and economic performance: empirical evidence from Malaysia." International Journal of Trade, Economics and Finance 1(3): 261-267.

Marc Hormann and J. D. Joern Carlos Kuntze (2012) Delivering on the energy efficiency promise in the middle east energy

Mohamed Ekhlat, I. M. S. a. N. M. K. (2007) Energy Efficiency and Renewable Energy

Libya - National study. Mediterranean and National Strategies for Sustainable Development: Priority Field of Action 2: Energy and Climate Change

Olayiwola, K. and H. Okodua (2009). Foreign direct investment, non-oil exports, and economic growth in Nigeria: a causality analysis. Annual Conference of African Econometric Society, Abuja Nigeria.

Sari, R., et al. (2008). "The relationship between disaggregate energy consumption and industrial production in the United States: An ARDL approach." Energy Economics 30(5): 2302-2313.

Siddiqui, M. (2012). "Energy Consumption and Economic Growth: A Case Study of Three SAARC Countries." Available at SSRN 2124639.

Skrabic, B. and N. Tomic-Plazibat (2009). "Evidence of the Long-run Equilibrium between Money Demand Determinants in Croatia." World Academy of Science, Engineering and Technology Working Paper(49).

Timmer, M. P. and A. Szirmai (2000). "Productivity growth in Asian manufacturing: the structural bonus hypothesis examined." Structural Change and Economic Dynamics 11(4): 371-392.

UEA (2012). "Energy consumption and production report." from http://www.eia.gov/countries/analysisbriefs/UAE/uae.pdf.

Wee, K. F., et al. (2008). "Energy consumption and carbon dioxide emission considerations in the urban planning process in Malaysia." Yean, T. S. (1997). "Determinants of productivity growth in the Malaysian manufacturing sector." ASEAN Economic Bulletin: 333-343. 